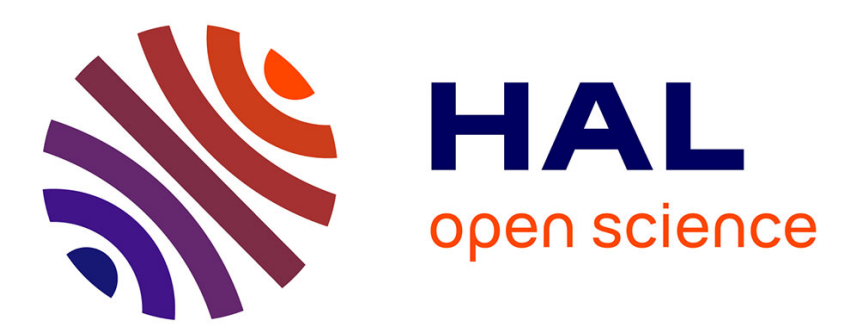

\title{
Influence of internally dropped-off plies on the impact damage of asymmetrically tapered laminated CFRP
}

Hakim Abdulhamid, Christophe Bouvet, Laurent Michel, Jacky Aboissière, Clément Minot

\section{- To cite this version:}

Hakim Abdulhamid, Christophe Bouvet, Laurent Michel, Jacky Aboissière, Clément Minot. Influence of internally dropped-off plies on the impact damage of asymmetrically tapered laminated CFRP. Acta Materialia, 2015, vol. 68, pp. 110-120. 10.1016/j.compositesa.2014.09.024 . hal-01094592

\section{HAL Id: hal-01094592 https://hal.science/hal-01094592}

Submitted on 12 Dec 2014

HAL is a multi-disciplinary open access archive for the deposit and dissemination of scientific research documents, whether they are published or not. The documents may come from teaching and research institutions in France or abroad, or from public or private research centers.
L'archive ouverte pluridisciplinaire HAL, est destinée au dépôt et à la diffusion de documents scientifiques de niveau recherche, publiés ou non, émanant des établissements d'enseignement et de recherche français ou étrangers, des laboratoires publics ou privés. 


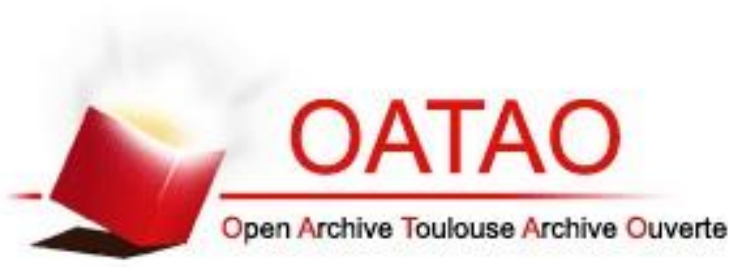

\section{Open Archive Toulouse Archive Ouverte (OATAO)}

OATAO is an open access repository that collects the work of Toulouse researchers and makes it freely available over the web where possible.

This is an author-deposited version published in: http://oatao.univ-toulouse.fr/ Eprints ID: 12129

To link to this article: DOI: 10.1016/j.compositesa.2014.09.024

URL: http://dx.doi.org/10.1016/j.compositesa.2014.09.024

To cite this version: Abdulhamid, Hakim and Bouvet, Christophe and Michel, Laurent and Aboissière, Jacky and Minot, Clément Influence of internally dropped-off plies on the impact damage of asymmetrically tapered laminated CFRP. (2015) Composites Part A: Applied Science and Manufacturing, vol. 68. pp. 110-120. ISSN 1359-835X

Any correspondence concerning this service should be sent to the repository administrator: staff-oatao@inp-toulouse.fr 


\title{
Influence of internally dropped-off plies on the impact damage of asymmetrically tapered laminated CFRP
}

\author{
Hakim Abdulhamid ${ }^{\mathrm{a}, \mathrm{b}, *}$, Christophe Bouvet ${ }^{\mathrm{a}}$, Laurent Michel ${ }^{\mathrm{a}}$, Jacky Aboissière ${ }^{\mathrm{b}}$, Clément Minot $^{\mathrm{b}}$ \\ a Université de Toulouse; INSA, UPS, Mines ALBI, ISAE; ICA (Institut Clément Ader), ISAE (Institut Supérieur de l'Aéronautique et de l'Espace), 10, avenue Edouard Belin, \\ BP 54032-31055 Toulouse Cedex 4, France \\ ${ }^{\mathrm{b}}$ Sogeti High Tech, Avenue Escadrille Normandie Niemen, Parc du Millénaire, 31703 Blagnac, France
}

A R T I C L E I N F O

Keywords:

A. Carbon fibre

B. Impact behaviour

C. Damage mechanics

Ply drop-off

\begin{abstract}
A B S T R A C T
This paper presents an experimental study of low velocity impact response of carbon/epoxy asymmetrically tapered laminates. The tests are realised at energy between 10 and $30 \mathrm{~J}$ on two types of layup with multiple terminated plies. The type and localisation of damage are analysed using C-scan and micrographs. Then, the data is compared with the response of corresponding respective plain laminate. The effects of some tapering parameters (taper angle, drop-off disposition and configuration) on the impact damage mechanisms are also investigated. Very similar impact damage phenomena are found between tapered and plain laminates. The presence of material discontinuity due to the resin pocket affects less the damage mechanism than the structural difference between the thick and the thin sections.
\end{abstract}

\section{Introduction}

In order to achieve optimum weight reduction of a structure like thin walled or beam structural elements, part thickness needs to be tailored according to local loads distribution. In composite structures, thickness tapering cannot be achieved in a continuous way. Plies must be terminated or dropped off at discrete location over the part. Additionally, as an effect of the manufacturing process, a triangular-shape resin-rich pocket is generally present at the end of a dropped ply. Effects of those geometry and material discontinuities on the damage mechanism under static and fatigue loadings have already been significantly studied [1-7]. In the tapered region, ply drop-off generates high inter-laminar stress concentration $[3,8]$ since the load carried by the dropped plies must be transferred to continuous plies through the inter-plies resin layers and the resin-rich pocket. This stress concentration triggers premature failure initiated by matrix cracking and delamination $[4-7,9]$. Both tensile and compressive strength are reduced when compared with the corresponding strengths of the thin section [10]. For instance, Curry and Johnson [4] found that the compressive strength ratio between the thin section and the tapered specimen is equal to the ratio of compliance between the thin

* Corresponding author at: Université de Toulouse: INSA, UPS, Mines ALBI, ISAE; ICA (Institut Clément Ader), ISAE (Institut Supérieur de l'Aéronautique et de l'Espace), 10, Avenue Edouard Belin, BP 54032-31055 Toulouse Cedex 4, France.

E-mail address: hakim.abdulhamid@isae.fr (H. Abdulhamid). and the thick section. Under fatigue loading, Weiss et al. [11] reported that the propagation of delamination initiated at the resin pocket nearest to the thin section leads to the final rupture of the specimen.

Another important element in composite structures design is the "impact damage tolerance" (i.e. the capacity to sustain load in presence of damage). Here, it is worth noting the difference with "impact damage resistance" which is more the concern for high energy impact. In fact, low velocity/low energy impact loading is likely to happen during the lifecycle of a given structure. Minor impact events like maintenance tool drop or in-service debris impact on the runway are likely to happen. Many studies have shown how dangerous out-of-plane loading can be to composite laminates [12-17]. In fact, impact loading creates complex internal damage, generally considered as matrix cracking, delamination and fibre rupture. Even in the absence of visible external damage, the internal damage can propagate far beyond the impact point and significantly reduces the resistance of the structure below design loads. For thin composite laminates, the energy threshold for BVID (Barely Visible Impact Damage) at which external damage is detectable, generally corresponds already to a substantial loss in the plate compression strength [18].

Many authors have highlighted the importance of interactions between matrix cracking and delamination onset and propagation on the impact damage mechanism [12,19-21]. Since, the ply drop-off discontinuity is found to be prone to damage, it is therefore justified to investigate its response to impact loading. In literature, 
there are not many reports concerning the study of impact damage of ply drop-off. To the authors' knowledge, only one study done by Kairouz and Ball [22] is available in the open literature. They have tested T300/914C asymmetrically tapered specimens with $6.88 \mathrm{~mm}$ and $6.02 \mathrm{~mm}$ thickness respectively in the thick and thin sections. One sub-laminate of three plies, situated near the nonimpacted side is terminated at the mid-length of the specimen. They presented the evolution of delamination area for energy between $14 \mathrm{~J}$ and $42 \mathrm{~J}$ and concluded on the vulnerability regarding the initiation of delamination of the 3 plies drop-off using the stress field from a $2 \mathrm{D}$ bending numerical simulation. However, that unique study remains limited and there is a need for a more in-depth understanding of the subject. In this work, specimens with multiple dropped plies are considered to match with industrial type structures. Firstly, the location of delaminated interfaces and their propagation are discussed with regards to the tapered region. Secondly, results of plain and tapered laminates are compared. And finally, the effects on the damage mechanism of drop-off disposition, configuration and the taper angle are analysed.

\section{Experimental setup}

\subsection{Material and specimens}

Two tapered laminate layups (A and B) are considered in this study. Both specimens have the same range of thickness: $6 \mathrm{~mm}$ (A) and $6.25 \mathrm{~mm}$ (B) in the thick and $4 \mathrm{~mm}$ in the thin sections. This range of thickness is a classical characteristic of aircraft fuselage. For such application, one side of the structure needs to be flat and smooth to provide good aerodynamic properties. This requirement has led to choose a specimen geometry with only one tapered side as shown in Fig. 1. Test specimens are $250 \mathrm{~mm}$ long and the tapering starts at $125 \mathrm{~mm}$ from the edge of the thin section (Fig. 1). This size is $100 \mathrm{~mm}$ longer compared with the standardized $100 \times 150 \mathrm{~mm}^{2}$ specimen commonly used in low velocity impact because some space needs to be allocated for the attachment of tabs at each end of the specimen in anticipation of future CAI tests. During the CAI tests, tabs will compensate for the thickness difference between thick and thin sections.

In this work, the dropped-plies of the specimens are interspersed with continuous plies. Such configuration of ply drop-off presents a good resistance under static loadings according to the work of Vizzini and Lee [8] and is advocated by the aeronautical regulation [23]. The specimens are made from $0.25 \mathrm{~mm}$ thick T700GC/M21 carbon-epoxy unidirectional prepreg tapes manufactured by HEXCEL ${ }^{\infty}$. The mechanical properties of the material obtained from experimental testing $[24,25]$ are provided in Table 1.

In the case of type A specimens, 8 in 24 plies are dropped-off. All the terminated plies are oriented in the $0^{\circ}$ longitudinal direction of the laminate. In this layup, the number of potential interface of
Table 1

Mechanical properties of T700GC/M21 [24,25].

\begin{tabular}{lll}
\hline$\rho$ & Density & $1600 \mathrm{~kg} / \mathrm{m}^{3}$ \\
$E_{1}^{T}$ & Tensile Young's modulus in fibre direction & $130 \mathrm{GPa}$ \\
$E_{1}^{C}$ & Compressive Young's modulus in fibre direction & $100 \mathrm{GPa}$ \\
$E_{2}$ & Transverse Young's modulus & $7.7 \mathrm{GPa}$ \\
$G_{12}$ & Shear modulus & $4.8 \mathrm{GPa}$ \\
$v_{12}$ & Poisson's ratio & 0.33 \\
$\varepsilon_{1}^{T 0}$ & Tensile failure strain in fibre direction & 0.016 \\
$\varepsilon_{1}^{C 0}$ & Compressive failure strain in fibre direction & -0.0125 \\
$\sigma_{2}^{T 0}$ & Transverse tensile strength & $60 \mathrm{MPa}$ \\
$\sigma_{12}^{0}$ & In-plane shear strength & $110 \mathrm{MPa}$ \\
\hline
\end{tabular}

delamination is reduced by grouping plies by pairs. The layup in the thin section is chosen to be the same as a previously studied plain plate [26] to enable the comparison of damage. For type B specimens, the layup contains 25 plies, 9 of which are droppedoff. It was designed following AIRBUS composite design rules [23]. Plies with all orientations $(0,45,-45,90)$ are terminated. Compared with type A specimens, the number of ply interfaces is increased by separating some plies of the same orientation. Also, there are some partially dropped groups of plies (Fig. 2(a)) which are obtained by terminating only one ply in a group of two or three plies of the same orientation. To assess the damage vulnerability of tapered laminates, for both layups, plain laminate with the corresponding thin section layup is also considered.

Regarding the parametric study, two taper angles are tested: a steep slope of $17 \%$ and a shallow slope of $10 \%$. Since ply thickness is $2.5 \mathrm{~mm}$, the step spacing is then respectively equal to 1.5 and $2.5 \mathrm{~mm}$. To modify the drop-off configuration in layup A, the groups of plies are dropped-off in two different manners: in a staggered way (Fig. 2(b)) for $A^{\text {st }}$ specimens and simultaneously (Fig. 2(c)) for $A^{\text {si }}$. For type $B$ layup, two configurations $B^{1}$ and $B^{2}$ are also manufactured by changing the order of dropping the plies. The nomenclature of the tapered specimens is presented in Table 2. It is defined as the type $\left(A^{\text {st }}, A^{\text {st }}, B^{1}, B^{2}\right)$ followed by the drop-off spacing $(1.5,2.5)$ in subscript. The plain laminates are respectively designated as $\mathrm{A}^{\mathrm{P}}$ and $\mathrm{B}^{\mathrm{P}}$. Detailed descriptions of the layups are provided in Table 3.

The consistency of the taper angle is ensured by controlling the step spacing between terminated plies with a microscopic screw driven ruler during layup; no mould was placed against the tapered face during the curing process. After the manufacturing process, the transition zone was observed under a microscope to assess the state of the drop-off. A triangular shape resin pocket is observed at the end of dropped plies, except for those close to a $90^{\circ}$ ply. For such plies, the $90^{\circ}$ ply material migrates inside the pocket. Curry and Johnson [4] have also reported similar observation for their specimens.

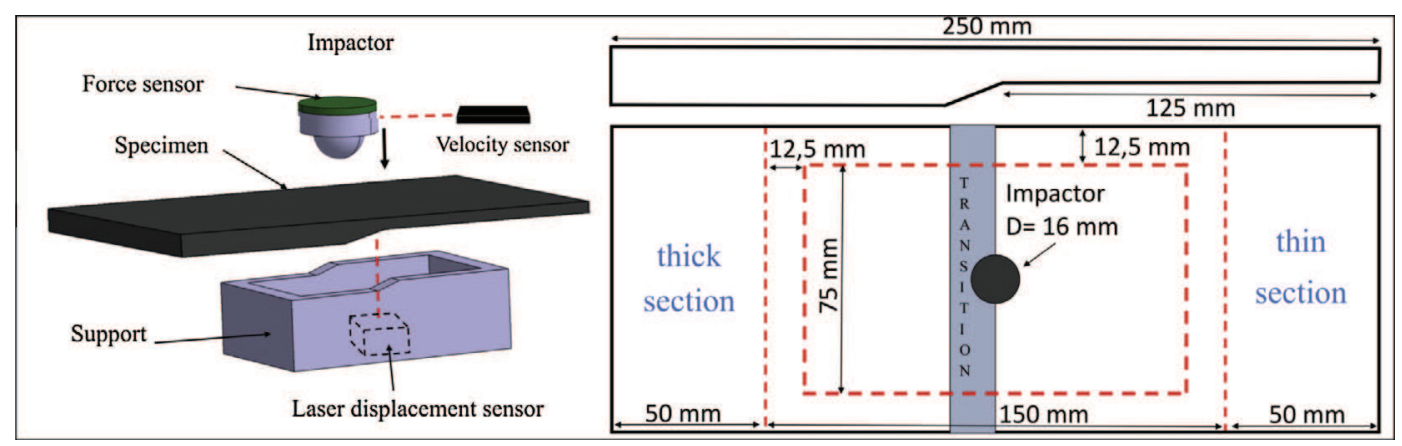

Fig. 1. Impact boundary conditions. (For interpretation of the references to colour in this figure legend, the reader is referred to the web version of this article.) 


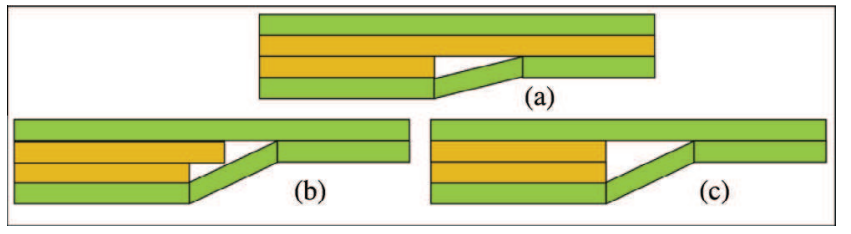

Fig. 2. Drop-off configurations (a - partially dropped-off, b - staggered drop-off, c simultaneously dropped). (For interpretation of the references to colour in this figure legend, the reader is referred to the web version of this article.)

Table 2

Tapered specimens nomenclature.

\begin{tabular}{llll}
\hline Layups & Configurations & Step spacing $(\mathrm{mm})$ & Nomenclature \\
\hline $\mathrm{A}$ & Staggered & 1.5 & $\mathrm{~A}_{1.5}^{\mathrm{st}}$ \\
& Simultaneous & 5 & $\mathrm{~A}_{2.5}^{\mathrm{si}}$ \\
& & 3 & $\mathrm{~A}_{1.5}^{\mathrm{si}}$ \\
$\mathrm{B}$ & 1 & 2.5 & $\mathrm{~B}_{2.5}^{1}$ \\
& & 1.5 & $\mathrm{~B}_{1.5}^{1}$ \\
& 2 & 2.5 & $\mathrm{~B}_{2.5}^{2}$ \\
& & 1.5 & $\mathrm{~B}_{1.5}^{2}$ \\
\hline
\end{tabular}

\subsection{Test procedure}

Impact tests were performed using a drop weight testing rig. A guided $4 \mathrm{~kg}$-mass with a hemispherical indenter of $16 \mathrm{~mm}$ diameter is dropped from a specific height onto the specimen placed below. Specimens were impacted on the flat face; the opposite side being simply supported by a tapered base with a rectangular opening of $75 \times 125 \mathrm{~mm}^{2}$. This boundary condition is very similar to the Airbus standard AITM 1-0010 [27] defined for plain specimens. The impact target is the centre of the specimen which is located at the end of the thin section. The schematic diagram of the test setup is provided in Fig. 1.

Regarding the test measurement, a piezoelectric sensor is attached to the impactor to measure the impact force history and an optical sensor is placed at the level of the specimen to measure the initial impact velocity. Also, the deflection of the non-impacted face is measured using another optical sensor positioned below the specimen. All the data is acquired and recorded at a sampling rate of $200 \mathrm{kHz}$. The initial velocity and impact force history were then used to compute the evolution of velocity and displacement of the indenter throughout the test. A detailed description of the integration and data processing procedure is available in [28]. Post-impact damage analysis was conducted using C-scan techniques and microscopic observations.

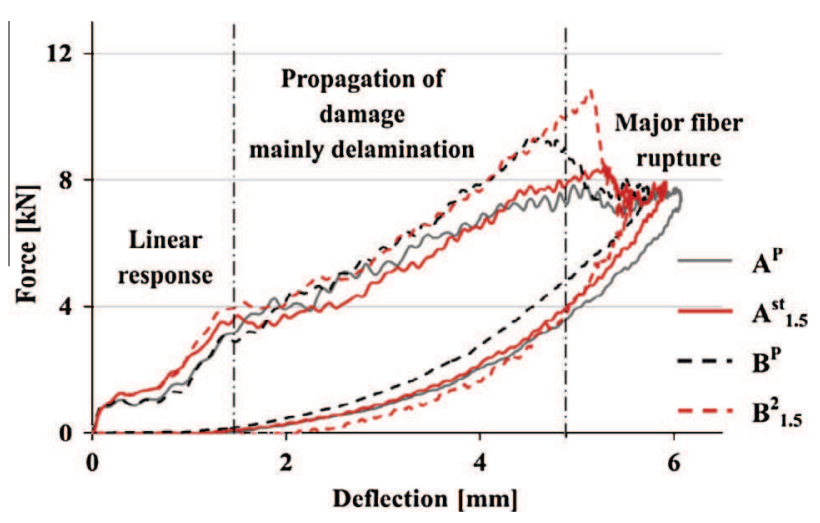

Fig. 3. Force-displacement curves for specimens impacted at $30 \mathrm{~J}$. (For interpretation of the references to colour in this figure legend, the reader is referred to the web version of this article.)

\section{Results}

\subsection{Force curves}

Force versus displacement curves of four different specimens impacted at $30 \mathrm{~J}$ are plotted in Fig. 3 for comparison. Tapered specimens $\left(A_{1.5}^{\text {st }}\right.$ and $\left.B_{1.5}^{1}\right)$ curves are very similar to the respective corresponding thin section plain laminate $\left(\mathrm{A}^{\mathrm{P}}\right.$ or $\left.\mathrm{B}^{\mathrm{P}}\right)$. The impact phases, from the damage mechanism point of view, are reflected in the changes of the force-displacement curve. Similarly to composite plain laminates, three major phases can be distinguished. The first phase corresponds mainly to the linear dynamic response of the system: impactor and plate. It lasts until the onset of first severe damage - in this case, delamination - when the force reaches around $4 \mathrm{kN}$. The second phase of the impact is characterized by the propagation of ply interfaces delamination. This propagation is as stable as for plain specimen given the strong similarity between the curves. The final phase is characterized by a drastic drop in the force which is commonly associated with fibre rupture. It happens shortly before the return of the indenter.

\subsection{Global results}

A summary of the impact results for tapered and plain specimens is presented in Table 4. For each test, data is presented in terms of: the impact and absorbed energies, the maximum filtered impact force and the maximum deflection of the plate during the test. Also provided are the projected delaminated area obtained

Table 3

Specimens layup. (For interpretation of the references to colour in this table legend, the reader is referred to the web version of this article.)

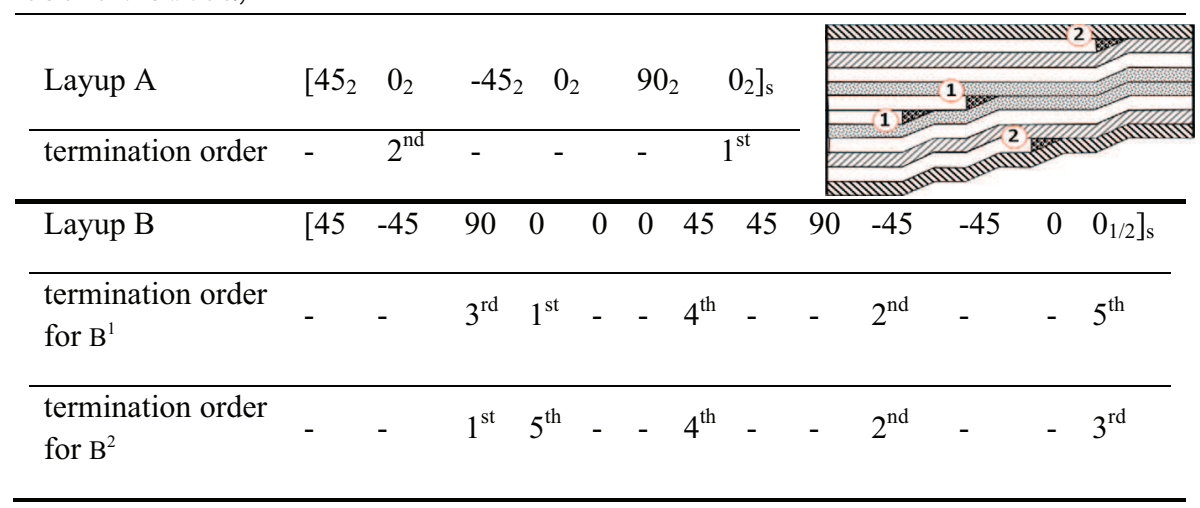




\section{Table 4}

Specimen results summary. (For interpretation of the references to colour in this table legend, the reader is referred to the web version of this article.)

\begin{tabular}{|c|c|c|c|c|c|c|}
\hline $\begin{array}{l}\text { Specimens } \\
\text { (1) }\end{array}$ & $\begin{array}{l}\text { Impact } \\
\text { Energy }\end{array}$ & $\begin{array}{c}\text { Delaminated } \\
\text { Area (2) }\end{array}$ & $\begin{array}{l}\text { Dissipated } \\
\text { Energy }\end{array}$ & $\begin{array}{l}\text { Maximum } \\
\text { Force }\end{array}$ & $\begin{array}{l}\text { Maximum } \\
\text { Deflection }\end{array}$ & $\begin{array}{c}\text { Permanent } \\
\text { Indentation }\end{array}$ \\
\hline $\mathrm{A}_{2.5}^{\mathrm{si}}$ & $10.3 \mathrm{~J}$ & $594 \mathrm{~mm}^{2}$ & $3.9 \mathrm{~J}(37 \%)$ & $6.6 \mathrm{kN}$ & $3.0 \mathrm{~mm}$ & $0.09 \mathrm{~mm}$ \\
\hline $\mathrm{A}^{\mathrm{si}}{ }_{1.5}$ & $10.5 \mathrm{~J}$ & $684 \mathrm{~mm}^{2}$ & $4.5 \mathrm{~J}(43 \%)$ & $6.6 \mathrm{kN}$ & $3.1 \mathrm{~mm}$ & $0.09 \mathrm{~mm}$ \\
\hline $\mathrm{A}_{2.5}^{\mathrm{si}}$ & $20.4 \mathrm{~J}$ & $1828 \mathrm{~mm}^{2}$ & $11 \mathrm{~J}(53 \%)$ & $7.5 \mathrm{kN}$ & $4.7 \mathrm{~mm}$ & $0.16 \mathrm{~mm}$ \\
\hline $\mathrm{A}_{1.5}^{\mathrm{st}}$ & $19.9 \mathrm{~J}$ & $1800 \mathrm{~mm}^{2}$ & $8.9 \mathrm{~J}(44 \%)$ & $8.0 \mathrm{kN}$ & $4.6 \mathrm{~mm}$ & $0.23 \mathrm{~mm}$ \\
\hline $\mathrm{A}_{1.5}^{\mathrm{si}}$ & $20.6 \mathrm{~J}$ & $2288 \mathrm{~mm}^{2}$ & $11.8 \mathrm{~J}(57 \%)$ & $7.5 \mathrm{kN}$ & $4.6 \mathrm{~mm}$ & $0.20 \mathrm{~mm}$ \\
\hline $\mathbf{A}^{\mathbf{P}}$ & 30.1 J & $2827 \mathrm{~mm}^{2}$ & $19.8 \mathrm{~J}(65 \%)$ & $7.8 \mathrm{kN}$ & $6.0 \mathrm{~mm}$ & $0.40 \mathrm{~mm}$ \\
\hline $\mathrm{A}^{\mathrm{si}}{ }_{2.5}$ & $30.6 \mathrm{~J}$ & $2655 \mathrm{~mm}^{2}$ & $19.7 \mathrm{~J}(64 \%)$ & $8.2 \mathrm{kN}$ & $6.1 \mathrm{~mm}$ & $0.29 \mathrm{~mm}$ \\
\hline $\mathrm{A}^{\mathrm{st}}{ }_{1.5}$ & $29.1 \mathrm{~J}$ & $2730 \mathrm{~mm}^{2}$ & $18.7 \mathrm{~J}(65 \%)$ & $8.4 \mathrm{kN}$ & $5.9 \mathrm{~mm}$ & $0.40 \mathrm{~mm}$ \\
\hline $\mathrm{B}_{2.5}^{1}$ & $10.3 \mathrm{~J}$ & $421 \mathrm{~mm}^{2}$ & $4.6 \mathrm{~J}(45 \%)$ & $6.4 \mathrm{kN}$ & $2.9 \mathrm{~mm}$ & $0.07 \mathrm{~mm}$ \\
\hline $\mathrm{B}_{2.5}^{2}$ & $10.1 \mathrm{~J}$ & $540 \mathrm{~mm}^{2}$ & $4.0 \mathrm{~J}(40 \%)$ & $6.4 \mathrm{kN}$ & $3.0 \mathrm{~mm}$ & $0.07 \mathrm{~mm}$ \\
\hline $\mathrm{B}_{1.5}^{1}$ & $10.3 \mathrm{~J}$ & $387 \mathrm{~mm}^{2}$ & $5.9 \mathrm{~J}(58 \%)$ & $6.3 \mathrm{kN}$ & $2.9 \mathrm{~mm}$ & $0.08 \mathrm{~mm}$ \\
\hline $\mathrm{B}_{1.5}^{2}$ & $9.7 \mathrm{~J}$ & $343 \mathrm{~mm}^{2}$ & $4.6 \mathrm{~J}(48 \%)$ & $6.4 \mathrm{kN}$ & $2.8 \mathrm{~mm}$ & $0.07 \mathrm{~mm}$ \\
\hline $\mathrm{B}_{2.5}^{1}$ & $20.4 \mathrm{~J}$ & $1106 \mathrm{~mm}^{2}$ & $10.4 \mathrm{~J}(51 \%)$ & $8.9 \mathrm{kN}$ & $4.3 \mathrm{~mm}$ & $0.13 \mathrm{~mm}$ \\
\hline $\mathrm{B}_{2.5}^{2}$ & $20.3 \mathrm{~J}$ & $999 \mathrm{~mm}^{2}$ & $9.0 \mathrm{~J}(44 \%)$ & $9.0 \mathrm{kN}$ & $4.3 \mathrm{~mm}$ & $0.12 \mathrm{~mm}$ \\
\hline $\mathbf{B}^{\mathrm{P}}$ & $30.2 \mathrm{~J}$ & $1178 \mathrm{~mm}^{2}$ & $18.8 \mathrm{~J}(62 \%)$ & $9.4 \mathrm{kN}$ & $5.4 \mathrm{~mm}$ & $0.47 \mathrm{~mm}$ \\
\hline $\mathrm{B}_{2.5}^{1}$ & $30.6 \mathrm{~J}$ & $1357 \mathrm{~mm}^{2}$ & $20.3 \mathrm{~J}(66 \%)$ & $9.5 \mathrm{kN}$ & $5.5 \mathrm{~mm}$ & $0.31 \mathrm{~mm}$ \\
\hline $\mathrm{B}_{2.5}^{2}$ & $30.5 \mathrm{~J}$ & $1911 \mathrm{~mm}^{2}$ & $14.3 \mathrm{~J}(47 \%)$ & $11.5 \mathrm{kN}$ & $5.2 \mathrm{~mm}$ & $0.19 \mathrm{~mm}$ \\
\hline $\mathrm{B}_{1.5}^{1}$ & $31.1 \mathrm{~J}$ & $1596 \mathrm{~mm}^{2}$ & $21.5 \mathrm{~J}(69 \%)$ & $10.6 \mathrm{kN}$ & $5.4 \mathrm{~mm}$ & $0.24 \mathrm{~mm}$ \\
\hline $\mathrm{B}_{1.5}^{2}$ & $30.9 \mathrm{~J}$ & $1734 \mathrm{~mm}^{2}$ & $23.6 \mathrm{~J}(76 \%)$ & $10.8 \mathrm{kN}$ & $5.5 \mathrm{~mm}$ & $0.24 \mathrm{~mm}$ \\
\hline
\end{tabular}

Note: (1) the subscripts 1.5 and 2.5 correspond to the spacing between the ends of two successive dropped-off plies. (2) Area of projected delamination is computed from C-scan image.

from the C-scan image and the residual indentation measured with a stereo-correlation system at least $48 \mathrm{~h}$ after the test. In all, 20 tests have been realised and the results are fairly repeatable from one test to another. Some tests are performed twice in order to provide a specimen for microscopic observation.

For the plain laminates impacted at $30 \mathrm{~J}$, absorbed energy is comparable between $\mathrm{A}^{\mathrm{P}}$ and $\mathrm{B}^{\mathrm{P}}, 65 \%$ and $62 \%$ of the initial energy respectively. However, the projected delaminated area is $60 \%$ lower for $\mathrm{B}^{\mathrm{P}}$ compared with $\mathrm{A}^{\mathrm{P}}$ as a result of the higher number of plies interfaces in $\mathrm{B}^{\mathrm{P}}$ layup. As the number of interface increases, smaller projected area is needed to dissipate the impact initial energy. For both cases, the maximum impact force of the specimen is reached because there is a sudden drop of the peak force for $\mathrm{B}^{\mathrm{P}}$ and a plateau for $\mathrm{A}^{\mathrm{P}}$ (Fig. 3).

In the cases of tapered laminates, the tests are performed for a range of increasing nominal energy of 10,20 and $30 \mathrm{~J}$. For low impact energies ( 10 and $20 \mathrm{~J}$ ), the damage consists mainly of diffused matrix cracking and ply interface delamination. For those cases, the absorbed energy is around $40 \%$ of the impact energy. At $30 \mathrm{~J}$, a severe drop in the plate stiffness due to fibre rupture is observed and the absorbed energy increases up to 65-70\%. Furthermore, the dissipated energy of steeper specimens $\left(A_{1.5}, B_{1.5}\right)$ is slightly higher compared with the shallower ones $\left(A_{2.5}, B_{2.5}\right)$ but they still remain in the same range as for plain specimens. Regarding the delamination of tapered specimens, the damage area of A specimens remains higher (around 50\%) compared with B specimens. This observation is consistent with the data of plain laminates. However when comparing specimens A and B, impacted at $30 \mathrm{~J}$, with their respective plain laminate, the damage area is quite similar for type A specimens. This is contrary to type B results where the damage area is increased up to $60 \%$ for tapered specimens (Fig. 4(a)).

Permanent indentation is an important parameter to compare with the BVID $(0.25-0.5 \mathrm{~mm})$ and to assess the impact damage tolerance of composite plates. For tapered specimens it ranges from 0.07 to $0.4 \mathrm{~mm}$. At $30 \mathrm{~J}$, an important scattering of the indentation is observed for the B tapered specimens (Fig. 4(b)) and the values are smaller compared with the corresponding plain laminates.

\subsection{Internal damage}

NDT such as Ultrasonic system is widely used to identify the impact damage in CFRP laminates. It can provide information regarding both the damage area and through thickness localisation of material discontinuities like interfaces debonding. However, in the presence of ply drop-off, the ultrasonic wave signal can be disturbed by material discontinuities and plies inclination which makes it problematic to localise deep delamination. In the case of pristine specimen for example, it was difficult for the transceiver to record the reflected signal in the tapered region from both sides of the specimen. Another difficulty inherent to tapered specimen is the identification of the delaminated interface. Depending on the interface location in the thickness, its position may change on either side of the tapered region. Therefore, a particular interface can be represented by two different colours in the C-scan image, or a given colour may represent two different interfaces which makes the interpretation not straightforward.

In Fig. 5, a detailed C-scan image of specimen $A_{1.5}^{\text {st }}$ is presented. In this case for example, two different colours represent the interfaces between the group of plies $4 / 5[0,90]$ and $8 / 9[90,0]$. To facilitate the interpretation, delamination profile in the transition zone is represented next to the C-scan. The scan is carried out from the impacted face, in a rectangle area of $150 \times 100 \mathrm{~mm}^{2}$, centred at the impact point. Plies drop-off are represented by the horizontal dotted lines situated in the middle of the image. The dashed red line rectangle represents the impact boundary condition. The thick section is situated below the dotted lines and the thin one is in the upper part of the image.

Globally, the orientation of delaminated interfaces is governed by the same rule as for plain laminates: i.e. delamination propagates in the direction of the underlying ply. The conic evolution of delamination throughout the thickness, generally observed in plain laminates, is still verified apart from the propagation in the transverse direction of the specimen. The identified delamination profile shows that interfaces between continuous plies are more critical. Although a $1 \mathrm{~mm}$ thick $0^{\circ}$ terminated sub-laminate (plies drop-off (1)) is present at the mid-thickness, it does not trigger any delamination. Otherwise, there would have been another 

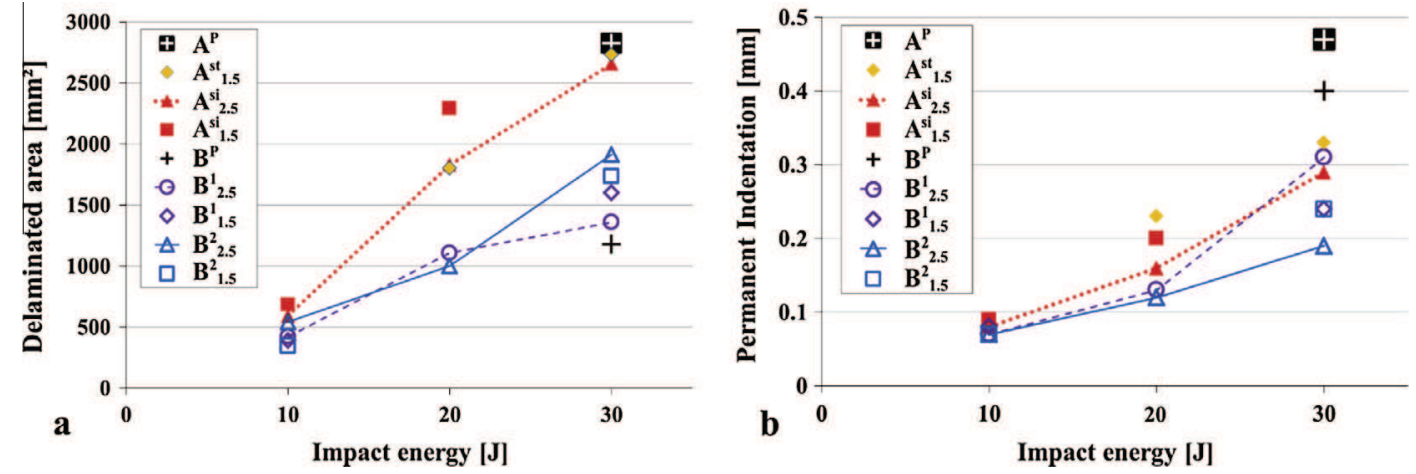

Fig. 4. (a) - Evolution of delamination area. (b) - Evolution of permanent indentation. (For interpretation of the references to colour in this figure legend, the reader is referred to the web version of this article.)

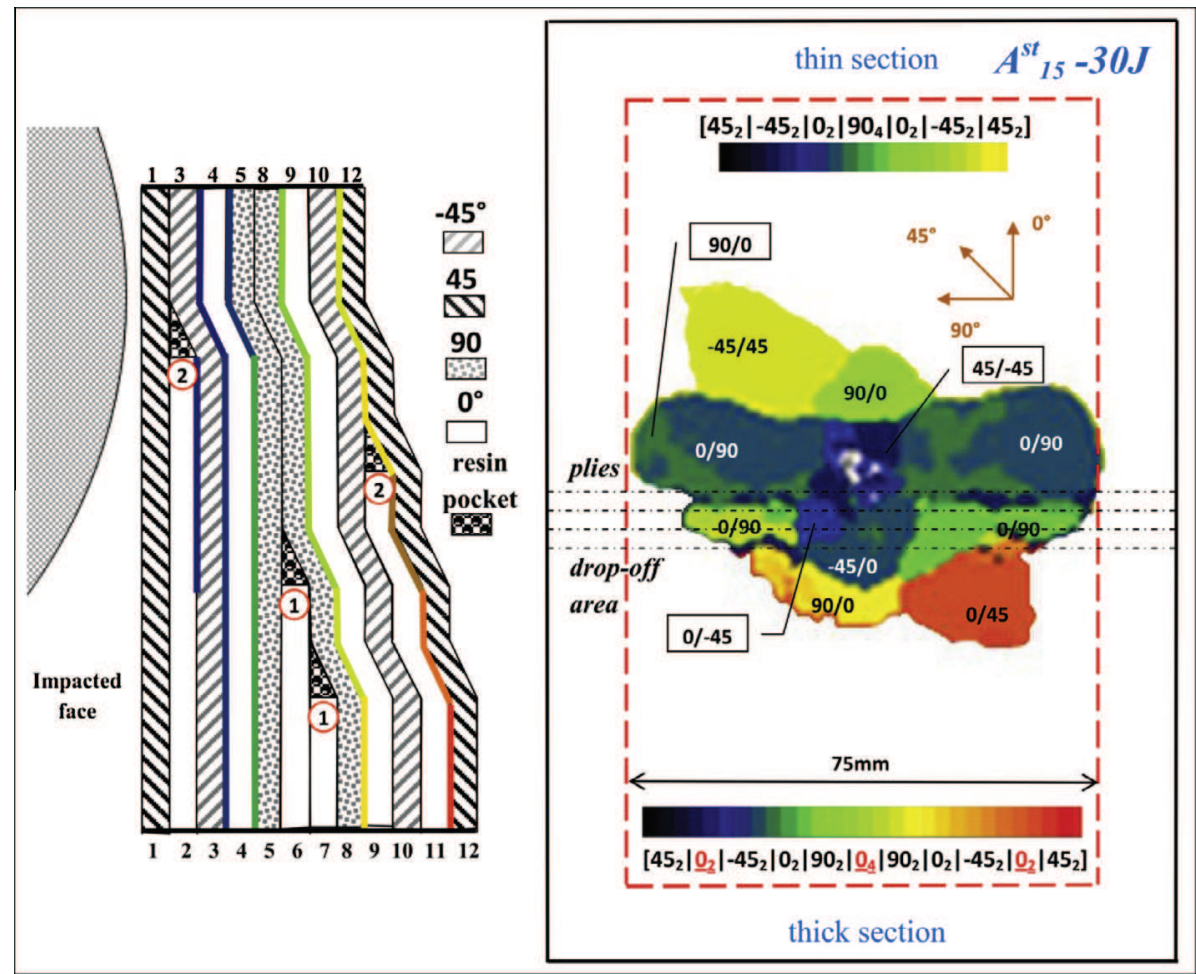

Fig. 5. C-scan from the impacted side of specimen $A_{1.5}^{\text {st }}$ impacted at $30 \mathrm{~J}$. (For interpretation of the references to colour in this figure legend, the reader is referred to the web version of this article.)

interface between the interfaces $4 / 5[0,90]$ shown in green and the ones shown in yellow 8/9 [90,0].

The micrograph of specimen $A_{1.5}^{\text {st }}$, in Fig. 6a, provides a comprehensive view of internal defects. The cutting plane is parallel to the longitudinal direction of the plate and passes through the impact point. Dense matrix cracking characterized by both small and big cracks are found below the indenter and farther in the thin section. Nevertheless, in the transition zone, the cracks are much less dense and consist of large trans-laminar failure that pilots the interface jump of delamination. The presence of multiple plies fibre rupture below the indenter correlates with the drop in the force curve in Fig. 3. Apart from the interface between the groups of plies 11/ $12[0,-45]$ situated near the non-impacted face, all the delaminated interfaces involve continuous plies (Fig. 6(a)). The micrograph confirms the absence of any damage around the $0^{\circ}$ terminated mid-thickness sub-laminate observed in the C-scan. Even though the ply drop-off is quite far from the impact point, the absence of any cracks around it induces that it is less critical to impact load.

For $\mathrm{B}_{1.5}^{1}$ specimens, the interpretation of the C-scan (Fig. 7) is much more complicated due to the existence of a higher number of ply interfaces and their proximity. Identification of interfaces using only the C-scan data is less accurate and it was conducted with information from micrographs. In order to lighten the view, only large delaminations are identified on the C-scan. These delaminations are found in the interfaces of both continuous and partially dropped plies. Despite the presence of dropped-off plies of different orientation, it is not possible to distinguish the most critical one in terms of delamination. It is only observed that, in the thin section, the largest delaminations propagate toward the $90^{\circ}$ transverse direction and that in the transition region they propagate toward the $45^{\circ}$ and $-45^{\circ}$ directions of the specimen.

The micrograph in Fig. 8 presents internal damage of $B_{1.5}^{1}$ specimen impacted at $30 \mathrm{~J}$. Three cross sections (A-A, B-B and 


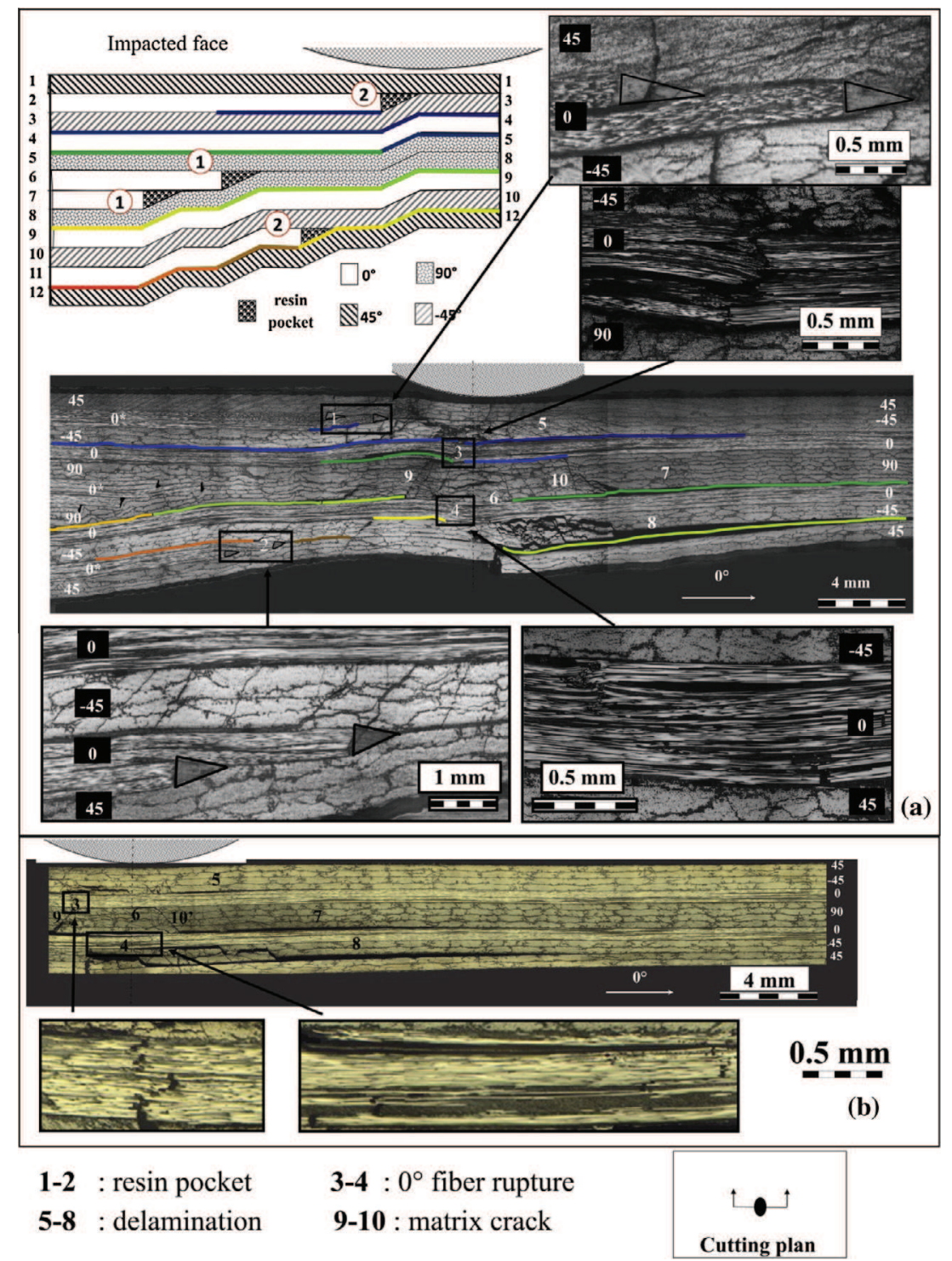

Fig. 6. Micrograph of (a) $-A_{1.5}^{\text {st }}$ specimen, (b) $-A^{\mathrm{P} *}$ specimen [26]. (For interpretation of the references to colour in this figure legend, the reader is referred to the web version of this article.)

$\mathrm{C}-\mathrm{C}$ ) are considered. The central image is the micrograph obtained at the section B-B. The zooms in Fig. 8(a-c) and (e) are schematic diagrams of local damage at different sections to show the evolution of damage in the transverse direction.

For this specimen, multiple matrix cracks and fibre ruptures are observed below the indenter (Fig. 8(d)). In the transition zone (Fig. 8(d)), there are some trans-laminar matrix cracks located far from the impact point. Those matrix cracks which pilot the interface jump of delamination are found in the proximity of ply drop-off. However, there is no crack observed in the resin pocket. Therefore, it is the inclination of ply due to the presence of a ply drop-off that generates additional out-of-plane shear responsible for crack initiation. Regarding the delamination, in addition to the ones identified in the C-scan, there are some smaller delaminations involving dropped plies. Actually, the presence of partially dropped layers has led to small delamination between two plies of the same orientation like the $0 / 0$ (Fig. 8(a)-ii) and $-45 /-45$ (Fig. 8(e)-ii). This type of $[\theta / \theta]$ interface delamination has not yet been reported in the case of impact damage. The micrograph shows that it does not propagate much farther and switches to a neighbour $[\theta / \beta]$ interface.
The analysis of delamination around ply drop-off at different cross-sections reveals that the delamination does not initiate at the ply drop-off (Fig. 8(e)). Dropped ply interfaces delaminate only when delamination of continuous plies interface reaches the resin pocket (Fig. 8(a), (b) and (e)) and that the orientation of the underlying ply is toward the resin pocket. To illustrate this idea, let's consider the zone represented in Fig. 8(a). In Fig. 8(a)-ii, obtained from cross-section $\mathrm{B}-\mathrm{B}$, the delamination of $[90,0]$ interface reaches the resin pocket (1). Since its propagation is in the longitudinal direction of the specimen, this delamination can progress and trigger a delamination between the continuous and terminated $0^{\circ}$ plies. However, at $45^{\circ}$ from the impact point, Fig. 8(a)-i obtained from cross section $\mathrm{C}-\mathrm{C}$, there is no delamination near the resin pocket (1) and this layer is not damaged.

\section{Discussion}

\subsection{Comparison with plain laminate}

Based on the force-displacement curves and the C-scan images, damage from tapered and plain laminates is compared to 


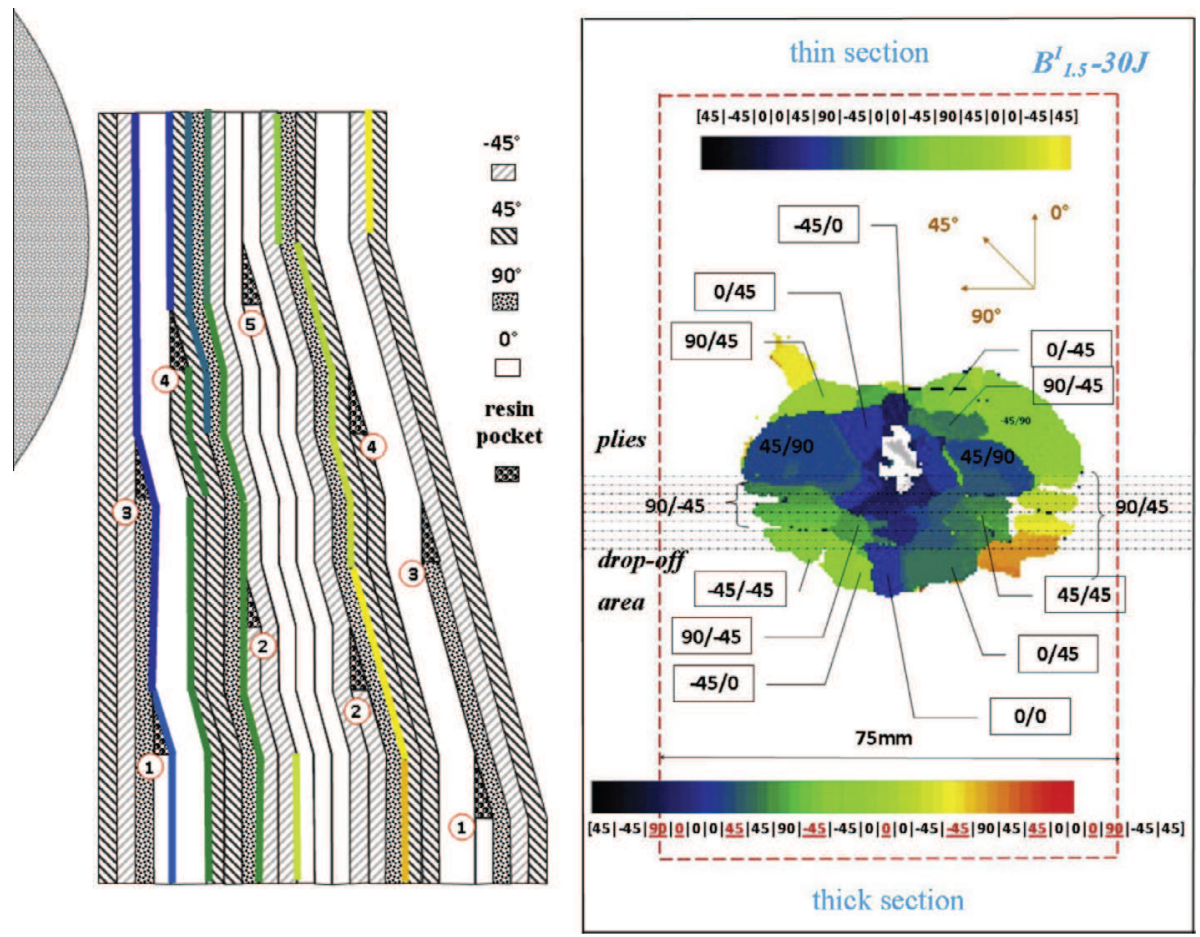

Fig. 7. C-scan from the impacted side of specimen $B_{1.5}^{1}$ impacted at $30 \mathrm{~J}$. (For interpretation of the references to colour in this figure legend, the reader is referred to the web version of this article.)

investigate the effect of the tapering in the damage mechanism. Note that plain laminate specimens are impacted at $30 \mathrm{~J}$ only. Regarding the force-displacement curves (Fig. 9), the response of tapered laminates are compared to the corresponding thin section plain laminate. For both specimens, the presence of the tapering does not modify the critical force for the onset of first damage. Nonetheless, the appearance of major fibre rupture seems to be affected by the tapering, but it is difficult to draw a conclusion given the scattering of composite materials. The existence of major fibre rupture, recorded on the force-displacement curve, affects significantly the value of permanent indentation as it was already reported by He et al. [29]. Besides that, permanent indentation increases with the value of additional deflection recorded after the fibre rupture during the impact. This additional deflection corresponds to the difference between the maximum displacement of the impactor and its displacement at major fibre rupture as presented in Fig. 11(a). Fig. 11(b) shows the correlation between permanent indentation and additional deflection of specimens impacted at $30 \mathrm{~J}$. Consequently, the variation of onset of fibre rupture and additional deflection after rupture explain the variation of permanent indentation between plain and tapered laminates. Although permanent indentation of tapered laminates is found to be lower compared to plain laminates, it is not possible to highlight a tendency of the effect of the tapering angle on fibre rupture or permanent indentation.

As regards to delamination in Fig. 10, the same interfaces are affected between plain laminates and the thin section of tapered laminates. For type A specimens particularly, delamination shape is comparable with a slightly larger propagation in the $90^{\circ}$ transverse direction of tapered specimens. Nonetheless, for type B specimens, differences in delamination shape are clearly visible. They are mainly observed in the first interfaces, especially for the ones that propagate in the transverse direction. As a result of the ply drop-offs, delamination is no more confined in a small area around the impact point as it should be for type B plain laminate layup because it has many ply interfaces. Additionally, some new interfaces $[\theta / \theta]$ involving partially dropped plies are also delaminated for tapered $B$ specimens.

For $A^{P}$ specimen, a micrograph from Bouvet et al. [26] is also available in Fig. 6(b). This specimen is named $A^{P *}$. The damage was created by quasi-static indentation test under the impact boundary conditions. The maximum deflection was $6.10 \mathrm{~mm}$ which is equivalent to the displacement of a $30 \mathrm{~J}$ impact on tapered specimen. For T700GC/M21, Bouvet et al. [26] have demonstrated that quasi-static indentation and low velocity impact give very similar damage. Note the strong similarity existing between the two specimens in terms of matrix cracks, delamination and fibre rupture.

\subsection{Effects of the tapering parameters}

The effects of three drop-off parameters: step spacing, configuration and disposition are investigated in this section. The comparison of the force-displacement curves of various specimens (Fig. 9(a) and (b)) shows that those three parameters have no significant effect either on the onset of damage or on the curve evolution. The only observed variation is related to the instant and the severity of tensile fibre rupture at the third phase of the impact loading between steep and shallow tapered specimens. For example, for specimens $B_{1.5}^{1}$ and $B_{1.5}^{2}$ impacted at $30 \mathrm{~J}$, there is a sudden $4 \mathrm{kN}$ loss when the impact force reaches $10.5 \mathrm{kN}$ due to simultaneous fibre rupture in multiple plies (Fig. 9). Nonetheless, specimens with shallow angle reveal less severe loss, i.e. $\mathrm{B}_{2.5}^{1}$ presents a $1.5 \mathrm{kN}$ drop at $9.5 \mathrm{kN}$ and $B_{2.5}^{2}$ has no force drop until $11.5 \mathrm{kN}$. Yet, it is difficult to draw a clear conclusion with the small number of tests and the scattering of composite material.

Regarding the delamination, its evolution with respect to the impact energy is presented for all specimens in Fig. 10. The comparison of $A_{1.5}$ with $A_{2.5}$ specimens shows that the propagation of delaminations toward the transverse direction is more pronounced for steep specimens. This comparison is only valid when impact energy is not enough to lead to major fibre rupture (10 and $20 \mathrm{~J}$ ). 


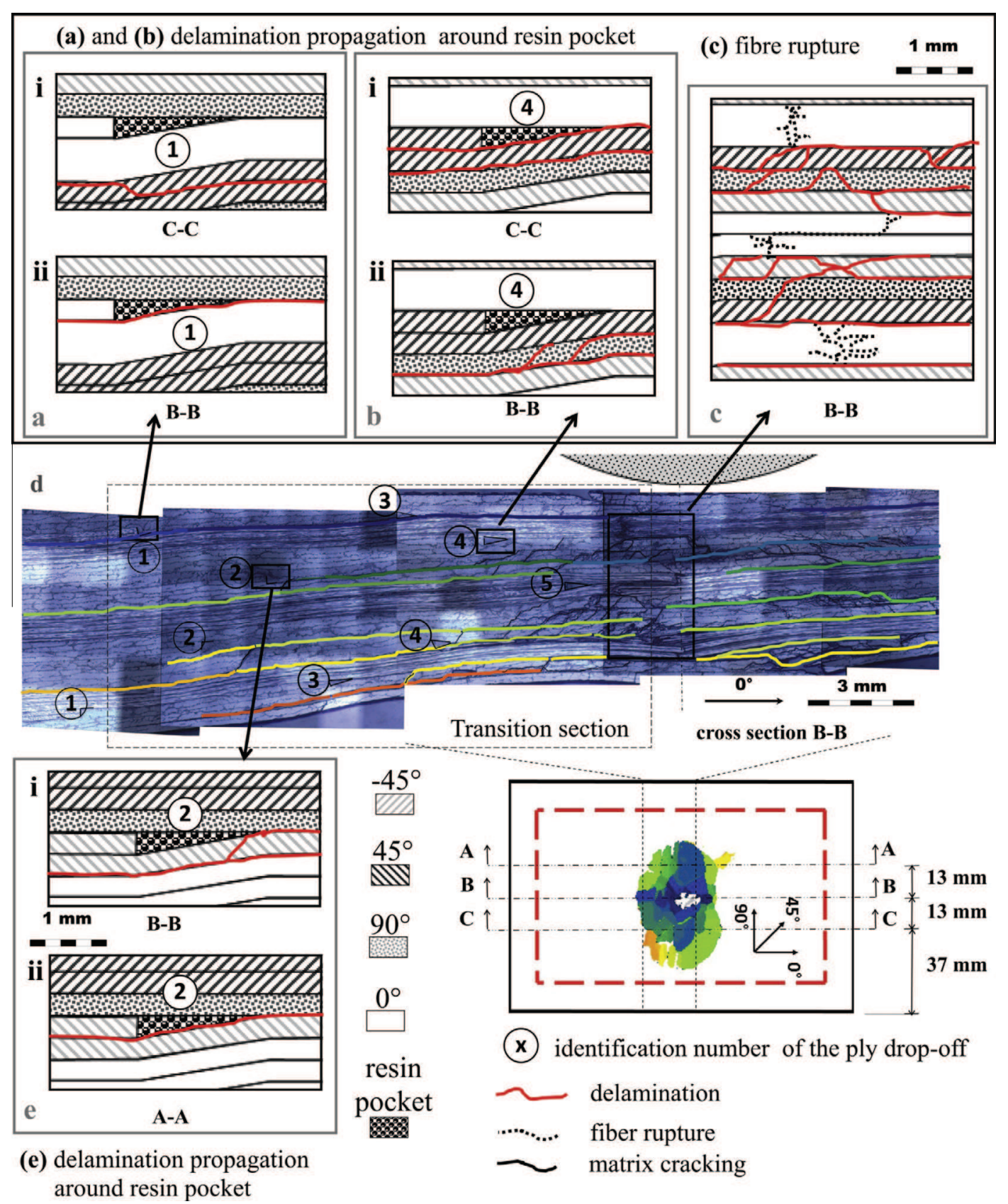

Fig. 8. Micrograph of $B_{1.5}^{1}$ specimen impacted at $30 \mathrm{~J}$. (For interpretation of the references to colour in this figure legend, the reader is referred to the web version of this article.)
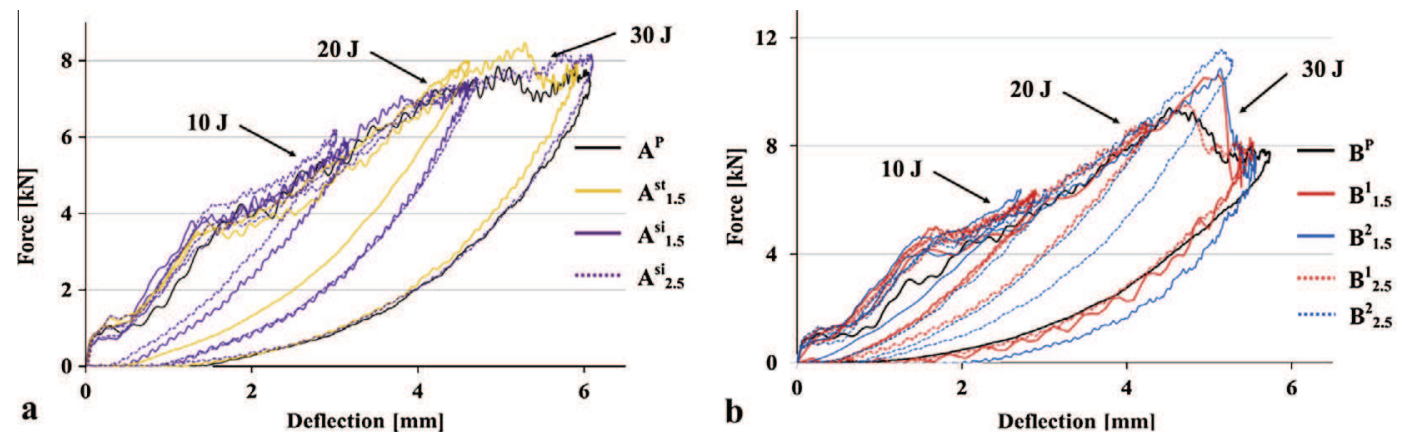

Fig. 9. Evolution of force-displacement curves for (a) - type A specimens, (b) - for type B specimens. (For interpretation of the references to colour in this figure legend, the reader is referred to the web version of this article.) 
$10 \mathrm{~J}$

$\mathrm{A}^{\mathrm{st}}{ }_{1.5}$

$\mathbf{A}_{1}^{\mathrm{si}}$

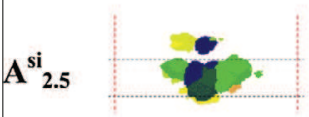

$\mathbf{A}^{\mathbf{P}}$

$\mathbf{B}^{1}{ }_{1.5}$

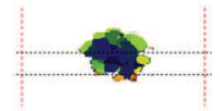

$\mathbf{B}^{1}{ }_{2.5}$

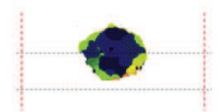

$\mathbf{B}^{2}{ }_{1.5}$

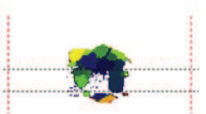

$\mathbf{B}^{2}{ }_{2.5}$

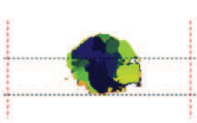

$\mathbf{B}^{\mathrm{P}}$
$20 \mathrm{~J}$
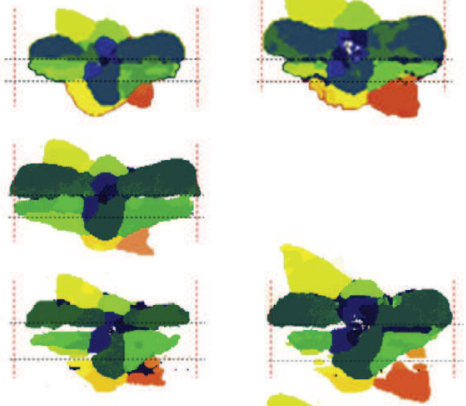

$6 \mathrm{~mm}$
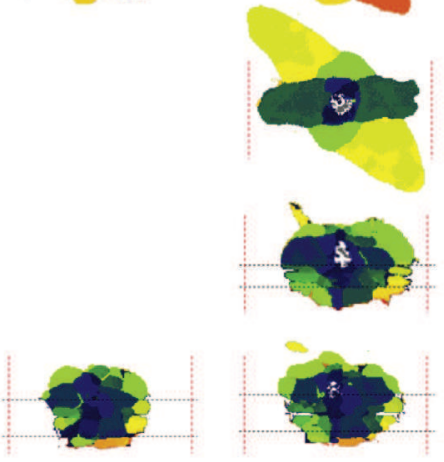

transition zone

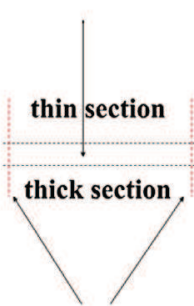

Longitudinal impact

supports

Fig. 10. Evolution of interface delamination for specimens A and B (C-scan from the impacted side). (For interpretation of the references to colour in this figure legend, the reader is referred to the web version of this article.)
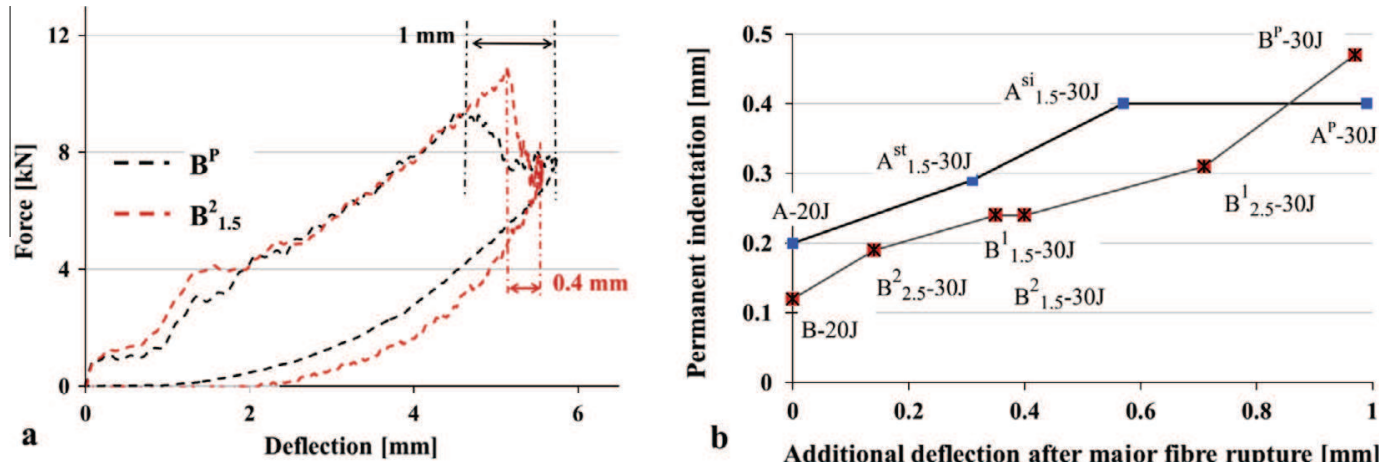

b

Additional deflection after major fibre rupture [mm]

Fig. 11. Permanent indentation versus additional deflection after major fibre rupture. (For interpretation of the references to colour in this figure legend, the reader is referred to the web version of this article.)

In fact, a steeper angle gives a smaller length of the transition zone and therefore the speed of delamination propagation toward the thick section is likely reduced earlier. As a result, more energy is available to be dissipated by delamination propagation through the transverse direction.

Concerning the disposition of ply drop-offs, Weiss et al. [11] showed that the order of dropping plies is an important parameter in the fatigue strength of tapered laminates. However, in this study, there is not any significant influence observed on the impact damage mechanism (Fig. 10). Even though there seems to be some differences in the delaminated interfaces of the transition zone between $\mathrm{B}^{1}$ and $\mathrm{B}^{2}$, those differences concern mainly the first interfaces close to the impact side and can be explained by the order in adding new plies in the layup. 
For the case of type A specimens, where the group of two plies were dropped in two different manners: simultaneous $\left(A_{1.5}^{\mathrm{si}}\right)$ and stagger $\left(A_{1.5}^{\text {st }}\right)$, a noticeable difference is observed on the delamination area. At $20 \mathrm{~J}$ impact energy, despite both configurations have the same tapering slope, the delamination area is $25 \%$ higher when the group of plies is dropped simultaneously $\left(\mathrm{A}_{1.5}^{\text {st }}\right)$. The propagation in the specimen transverse direction is the most affected by this modification. When two plies are dropped simultaneously, the neighbouring continuous plies are highly curved. As a result, the load passing through the inter-plies resin in the transition region is higher which explains the increase in delamination area.

\subsection{Tapered specimens damage mechanism}

The synthesis of information gathered in this study allows establishing the impact damage mechanism of tapered laminates. At low impact energy, as the micrographs have confirmed the absence of damage at ply drop-off, first damage must take place within the continuous plies in terms of matrix cracking. This leads to the delamination of the interfaces of continuous plies as found in the C-scan of low energy impacted specimens (Fig. 10). Delamination propagates in both the thin and thick sections at more or less the same rate in all directions. The shape and the propagation of delamination are governed by the same rules as for plain specimens. Resin pocket is only damaged if a delamination reaches its location and that the conditions of delamination propagation are fulfilled. Then, when delamination reaches the end of the transition region near the thick section, its propagation toward that direction is slowed down. The deceleration is due to the increase in local bending stiffness as more new plies are loaded. Simultaneously, the propagation in the transverse direction accelerates and the damage can reach the boundary conditions in presence of enough impact energy. Finally, major fibre rupture appears at the end of the impact load below the indenter.

The observation of micrographs reveals that ply drop-off resin pocket is less critical to damage than normal ply interface during impact. Even though, the resin pocket creates stress concentration, as it is located far enough from the impact point, the stress increase is not high enough to trigger any crack. The resin pocket is only damaged when delamination reaches its position and even then the crack does not propagate much far away as the stress concentration is confined near to the indenter. To understand this phenomenon, consider the stress field in a bending of a simply supported plate; the highest shear and normal stresses responsible for matrix cracking is localised below the indenter. This notion of confinement of the critical area explains the difference of resilience of tapered laminates when subjected to traction/compression loading and impact loading. In a traction/compression test, excluding the boundary effects, the stress is constant across the width of the specimen and therefore the first damage will be triggered by the stress concentration at the resin pocket. In the case of impact, as the location of ply drop-offs is quite far from the indenter, the stress concentration is not high enough to create cracks. Consequently, two main effects of the ply drop-off regarding delamination are observed: first, the creation of trans-laminar cracks in the neighbour plies that pilots the jump of delamination interface and second, the increase of delamination parallel to the ply dropoff axis which is essentially attributed to the structural effects of the thickness variation.

\section{Conclusion}

Impacts tests have been conducted on two typical tapered layups with a thickness varying from $4 \mathrm{~mm}$ to $6.25 \mathrm{~mm}$. Some taper parameters like drop-offs disposition, configuration and taper-angle were varied to investigate any effects on the damage. The impact energy level ranges from 10 to $30 \mathrm{~J}$. Impact damage assessment was realised using C-scan and micrographs. The results show that the global response of a tapered specimen is quite similar to the response of a plain specimen in terms of the force-displacement curve. The effects of ply drop-offs on the delamination shape is limited when the layup has few number of ply interfaces (A specimens). However in presence of laminate with many interfaces (B specimens); ply drop-off generates larger delamination area compared to plain laminates. In both cases, the overall delamination shape is elliptical with the major axis parallel to the ply drop-off. At high impact energy, the propagation of delamination is biased toward the thin section. Microscopic observations have shown that cracks do not necessarily initiate at the resin pocket. This behaviour is attributed to the confinement and complexity of the stress state in the impact loading. However, ply drop-off can trigger trans-laminar matrix cracking in the neighbour plies that can modify the propagation of delamination. The presence of partially dropped group of plies leads to small delamination between plies of the same orientation. The variation of the tapering angle and the order of adding new ply do not affect much the final damage of the specimen. However, delamination area increases when groups of plies are terminated simultaneously.

Compared to plain laminates, permanent indentation of tapered laminates is reduced due to the delay in fibre rupture. From a damage tolerance point of view, this difference can make tapered laminates more critical to impact. In the future, this research will be pursued to investigate the compression after impact of tapered laminates. Additionally, numerical analysis will be carried out to investigate the impact behaviour of tapered laminates, more specifically predicting the onset and growth of damage in matrix cracking, delamination and fibre rupture.

\section{Acknowledgement}

The authors gratefully acknowledge SOGETI HIGH TECH for the financial support of this Ph.D. program.

\section{References}

[1] Cui W, Wisnom MR, Jones M. New model to predict static strength of tapered laminates. Composites 1995;26:141-6.

[2] He K, Hoa S, Ganesan R. The study of tapered laminated composite structures: a review. Compos Sci Technol 2000;60:2643-57.

[3] Hitchen SA, Kemp RMJ. The effect of stacking sequence on impact damage in a carbon fibre/epoxy composite. Composites 1995;26:207-14.

[4] Curry JM, Johnsont ER. Effect of dropped plies on the strength of graphiteepoxy laminates. AIAA J 1992;30(2):449-56.

[5] Wisnom MR, Dixon R, Hill G. Delamination in asymmetrically tapered composites loaded in tension. Compos Struct 1996;35:309-22.

[6] Murri GB, O’Brien TK, Carl Q R. Fatigue life methodology for tapered composite flexbeam laminates. Am Helicopter Soc Forum 1997.

[7] Xing YM, Yun H, Dai FL. An experimental study of failure mechanisms in laminates with dropped plies. Compos Sci Technol 1999;59:1527-31.

[8] Vizzini AJ, Lee SW. Damage analysis of composite tapered beams. J Am Helicopter Soc 1995;40:43.

[9] Wisnom MR, Jones MI, Cui W. Failure of tapered composites under static and fatigue tension loading. AIAA J 1995;33:911-8.

[10] Steeves CA, Fleck NA. Compressive strength of composite laminates with terminated internal plies. Compos Part A Appl Sci Manuf 2005;36:798-805.

[11] Weiss a, Trabelsi W, Michel L, Barrau JJ, Mahdi S. Influence of ply-drop location on the fatigue behaviour of tapered composites laminates. Proc Eng 2010;2:1105-14.

[12] Abrate S. Impact on composite structures. Cambridge University Press; 2005.

[13] De Freitas M, Reis L. Composite failure: mechanisms on composite specimens compression after impact. Compos Struct 1998;42:365-73.

[14] Hongkarnjanakul N, Bouvet C, Rivallant S. Validation of low velocity impact modelling on different stacking sequences of CFRP laminates and influence of fibre failure. Compos Struct 2013;106:549-59.

[15] González EV, Maimí P, Camanho PP, Turon a, Mayugo Ja. Simulation of dropweight impact and compression after impact tests on composite laminates. Compos Struct 2012:94:3364-78.

[16] Reis L, de Freitas M. Damage growth analysis of low velocity impacted composite panels. Compos Struct 1997;38:509-15. 
[17] Rivallant S, Bouvet C, Hongkarnjanakul N. Failure analysis of CFRP laminates subjected to compression after impact: FE simulation using discrete interface elements. Compos Part A Appl Sci Manuf 2013;55:83-93.

[18] Richardson MOW, Wisheart MJ. Review of low velocity impact properties of composite materials. Compos Part A Appl Sci Manuf 1996;27:1123-31.

[19] Bouvet C, Castanié B, Bizeul M, Barrau J-J. Low velocity impact modelling in laminate composite panels with discrete interface elements. Int I Solids Struct 2009;46:2809-21.

[20] Allix O, Blanchard L. Mesomodeling of delamination: towards industria applications. Compos Sci Technol 2006;66:731-44.

[21] Renault M. Compression après impact d'une plaque stratifiée carbone époxyde - etude expérimentale et modélisation éléments finis associée. 1994.

[22] Kairouz KC, Ball J. Impact of ply drops. Beijing, China: ICCM; 2001.

[23] Airbus Industrie. Reference structure design principles for A350 XWB: composite design principles, vol. 2. Blagnac; 2008

[24] Guillon D. Etude des mécanismes d'absorption d'énergie lors de l'écrasement progressif de structures composites à base de fibre de carbone. Ph.D. DMSM ISAE. Université de Toulouse; 2008.
25] Prombut P. Caractérisation de la propagation de delaminage des stratifies composites multidirectionnels. Ph.D. DMSM ISAE. Université de Toulouse; 2007.

[26] Bouvet C, Hongkarnjanakul N, Rivallant S, Barrau J-J. Discrete modelling of inter- and intra-laminar failure for impact in composites. In: Abrate S, Castanié B, Rajapakse YDS, editors. Dyn. fail. compos. sandw. struct., vol. 192. Dordrecht: Springer Netherlands; 2013. p. 339-92.

[27] Airbus Industrie Test Method 1-0010. Fiber reinforced plastics determination of compression strength after impact. Blagnac Cedex: Airbus Industrie Engineering Directorate; 1999. p. 15.

28] Petit S, Bouvet C, Bergerot A, Barrau J-J. Impact and compression after impact experimental study of a composite laminate with a cork thermal shield. Compos Sci Technol 2007;67:3286-99.

[29] He W, Guan Z, Li X, Liu D. Prediction of permanent indentation due to impact on laminated composites based on an elasto-plastic model incorporating fibe failure. Compos Struct 2012. 